\title{
AS MÚLTIPLAS VISÕES DO MEIO AMBIENTE E OS IMPACTOS AMBIENTAIS
} - CAPÍtulo 14 -

\section{A INFLUÊNCIA DA URBANIZAÇÃO SOBRE PARÂMETROS BIÓTICOS E FÍSICOS EM ÁREA DE PRESERVAÇÃO PERMANENTE - APP}

\author{
Sara Dorea de Oliveira Santos; Andreza Silva e Silva; Luana Lima Souza; Ronilson Rosário Lobo.
} Antônio Pereira Júnior.

DOI: $10.4322 / 978-85-455202-1-4-14$

\section{INTRODUÇÃO}

O crescimento da degradação ambiental no Brasil é resultado de mudanças artificiais e perturbações no meio ambiente provocadas pela ação antrópica. Dessa forma, a urbanização tem uma relação direta com esse crescimento da assolação ambiental, por implicar na concentração de pessoas e de atividades produtivas sobre um espaço restrito, o que ocasiona impactos degradadores com efeitos sinérgicos e persistentes (JATOBÁ, 2011; LEVINO; MORAIS, 2009).

Quanto a compreensão de impacto ambiental, a Resolução CONAMA n. 001:1986 define o termo como qualquer alteração nos atributos físicos, químicos e biológicos do ambiente, sejam as tais provocadas por alguma forma de matéria ou energia, que tenha resultado da interferência antrópica no meio. Desta forma, estas alterações no meio podem afetar desde a saúde da população, como também, a segurança e o bem-estar da mesma, além de ser prejudicial também às práticas sociais e econômicas; ao equilíbrio da biota; às circunstâncias estéticas e sanitárias do ambiente e a qualidade dos recursos ambientais (BRASIL,1986).

Ademais, a necessidade de desenvolvimento da sociedade propõe um modelo de apropriação do espaço geográfico por meio da utilização de seus recursos naturais, dessa forma, analisar os impactos ambientais em áreas urbanas é de fundamental importância à elaboração, o progresso e o ordenamento das cidades. Essa crescente demanda por espaço físico propicia a ocupação desordenada e sem elaboração de áreas que deveriam servir como suporte à preservação ambiental, como as margens de córregos e rios consideradas Áreas de Preservação Permanente - APP (SILVA; SANTOS; GALDINO, 2016).

Dessa forma, as APP's situadas dentro do perímetro urbano merecem defesa proteção especial quando estiverem pressionadas pela expansão urbanísticas das áreas do entorno. Destaca-se a relevância de tais áreas devido estas ofertarem condições apropriadas à interação de componentes bióticos e abióticos, para que assim sejam executadas funções ecológicas determinantes à constância de variadas formas de vida, ou seja, as APP's desempenham papéis ambientais indispensáveis para a evolução de processos ecológicos essenciais (VARJABEDIAN; MECHILA, 2013).

Outrossim, para aferir o grau do dano ambiental de cada impacto faz-se necessário a avaliação de impacto ambiental, a qual consiste no reconhecimento e na estimativa das consequências futuras de uma ação ou proposta impactante. Ainda assim, o termo também é considerado uma abordagem sistemática, utilizada na identificação e avaliação dos impactos positivos e negativos, que podem surgir a partir da implementação de projetos, planos, programas ou políticas sobre o meio ambiente, contemplando seus componentes físicos, biológicos e socioeconômicos (GILBUENA, et al., 2013; SÁNCHEZ, 2013; SANTOS, 2013).

Em síntese, quais as consequências desencadeadas a partir do avanço da urbanização sobre áreas de preservação permanente? Com base neste questionamento justifica-se a presente pesquisa, a qual relaciona os parâmetros ambientais para descrever o cenário do entorno de um corpo hídrico, bem como estabelecer o grau de dependência entre tais parâmetros. Dessa forma, a relevância deste estudo está em expor como um processo de ações antrópicas interfere no equilíbrio de um ecossistema, por isso, o objetivo deste estudo é analisar a influência do processo de urbanização sobre as características naturais dos meios biótico e físico em uma Área de Preservação Permanente. 


\section{MATERIAL E MÉTODOS}

Os equipamentos utilizados para aquisição de dados in loco foram cedidos pelo laboratório de Qualidade Ambiental da Universidade do Estado do Pará - Campus VI Paragominas (Tabela 1).

Tabela 1 - Relação de materiais utilizados para adquirir dados in loco.

\begin{tabular}{|c|c|c|c|c|}
\hline Equipamentos & Marca & Modelo & Utilidade & Unidade \\
\hline Anemômetro & Squiser & $\mathrm{S} 30$ & $\begin{array}{l}\text { Mensuração do } \\
\text { vento }\end{array}$ & $\mathrm{m} / \mathrm{s}$ \\
\hline Decibilímetro & $\begin{array}{l}\text { Sound level } \\
\text { meter }\end{array}$ & Itdec 3000 & $\begin{array}{l}\text { Aferir o nível } \\
\text { sonoro }\end{array}$ & $\mathrm{dB}$ \\
\hline GPS & Etrex & $10 \mathrm{~S}$ & $\begin{array}{c}\text { Demarcar a } \\
\text { geolocalização }\end{array}$ & Graus/minutos/segundos \\
\hline Luxímetro & Instrutemp & ITLD 280 & $\begin{array}{c}\text { Mensurar a } \\
\text { intensidade da } \\
\text { Luz }\end{array}$ & (2) \\
\hline
\end{tabular}

Fonte: autores (2018).

Quanto aos equipamentos para coleta de dados in loco foram utilizados: 1 anemômetro (Figura 1a), para aferir a velocidade do vento; 1 decibelímetro (Figura 1b), para verificar a intensidade do ruído na área; 1 Global Positioning System - GPS (Figura 1c) e 1 luxímetro (Figura 1d) para conferir a luminosidade na área.

Figura 1 - Equipamentos utilizados para mensuração de dados in loco. A) Anemômetro; B) Decibelímetro, C) GPS e D) Luxímetro.

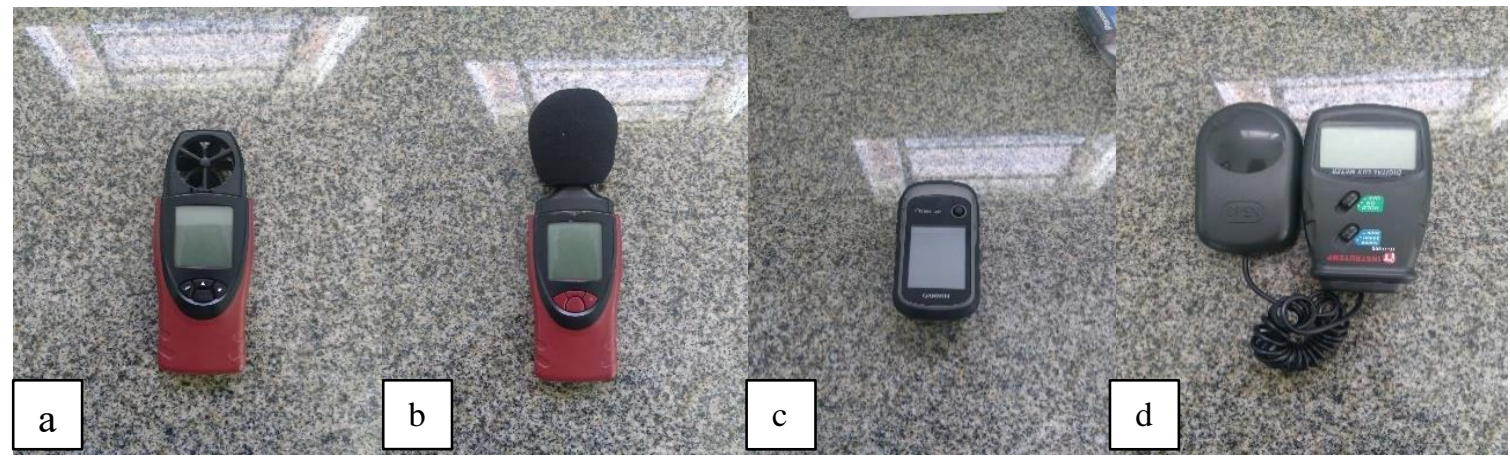

Fonte: autores (2018).

Ainda para adquirir os dados in loco foram usados instrumentos, dentre os quais:

- 1 biruta (Figura 2a) (um arco metálico com extremidade para encaixe na haste metálica e tecido leve) e 1 suporte de 2 m de comprimento, para auxiliar a identificar a direção do vento;

- 3 bússolas (Figura 2b), as quais serviriam para indicar a o sentido do vento;

- 4 diastímetros $(50 \mathrm{~m}, 50 \mathrm{~m}, 30 \mathrm{~m}$ e $20 \mathrm{~m}$ ) (Figura 2c), para delimitar o perímetro a ser analisado, auxiliar a definir a metragem de terra firme às margens do rio, auxiliar a definir a largura do rio e auxiliar a medir a circunferência das árvores lenhosas que estavam no perímetro demarcado ou áreas adjacentes;

- 3 réguas limnimétricas $(3 \mathrm{~m}, 2,10 \mathrm{~m} \mathrm{e} \mathrm{2,10} \mathrm{m)} \mathrm{(Figura} \mathrm{2d),} \mathrm{para} \mathrm{aferir} \mathrm{as} \mathrm{profundidades} \mathrm{do}$ rio e da margem do rio. 
Figura 2 - Instrumentos auxiliares na obtenção de dados in loco. A) Biruta e suporte para a biruta; B) Bússola, C) Diastímetros e D) Suporte para biruta e Régua limnimétrica.

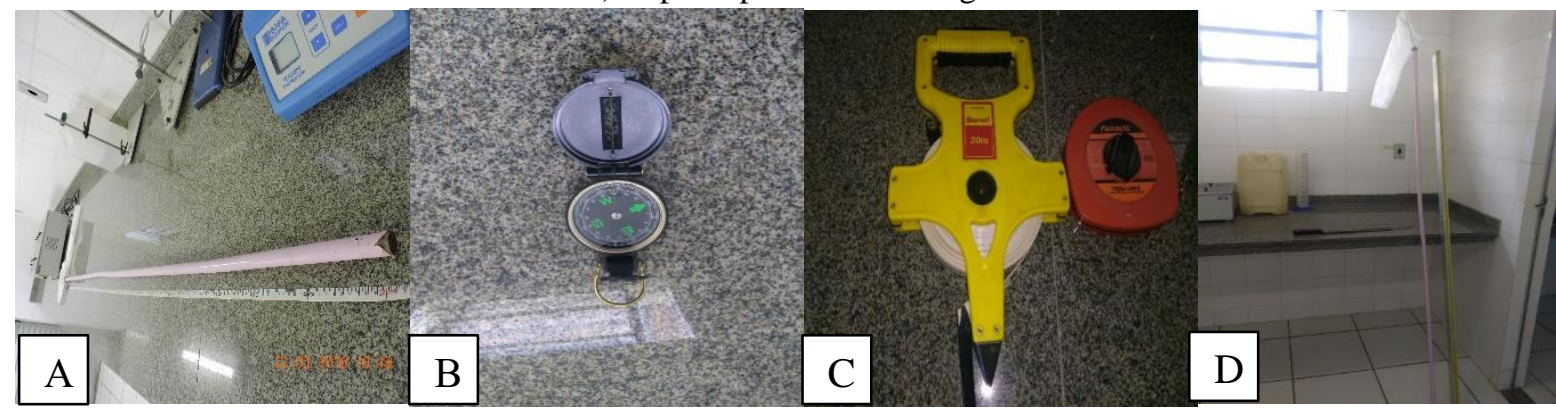

Fonte: autores (2018).

Ainda foram utilizados materiais como:

- 1 galão de material plástico de 20 L (Figura 3a), para captar água em um determinado tempo;

- 1 proveta de polietileno, com volume igual a $1000 \mathrm{ml}$ (Figura 3b), para determinar a quantidade de água que foi captada e, assim, estimar o volume de água;

- 4 facões, de $20 \mathrm{~cm}$ de lâmina (Figura 3c), para retirar o excesso de folhas presentes no percurso dentro do perímetro a ser estudado.

Figura 3 - Instrumentos utilizados para análise de dados in loco. A) Galão de 20 le proveta de 1000ml, B) Proveta de 1000 ml e C) Facão.

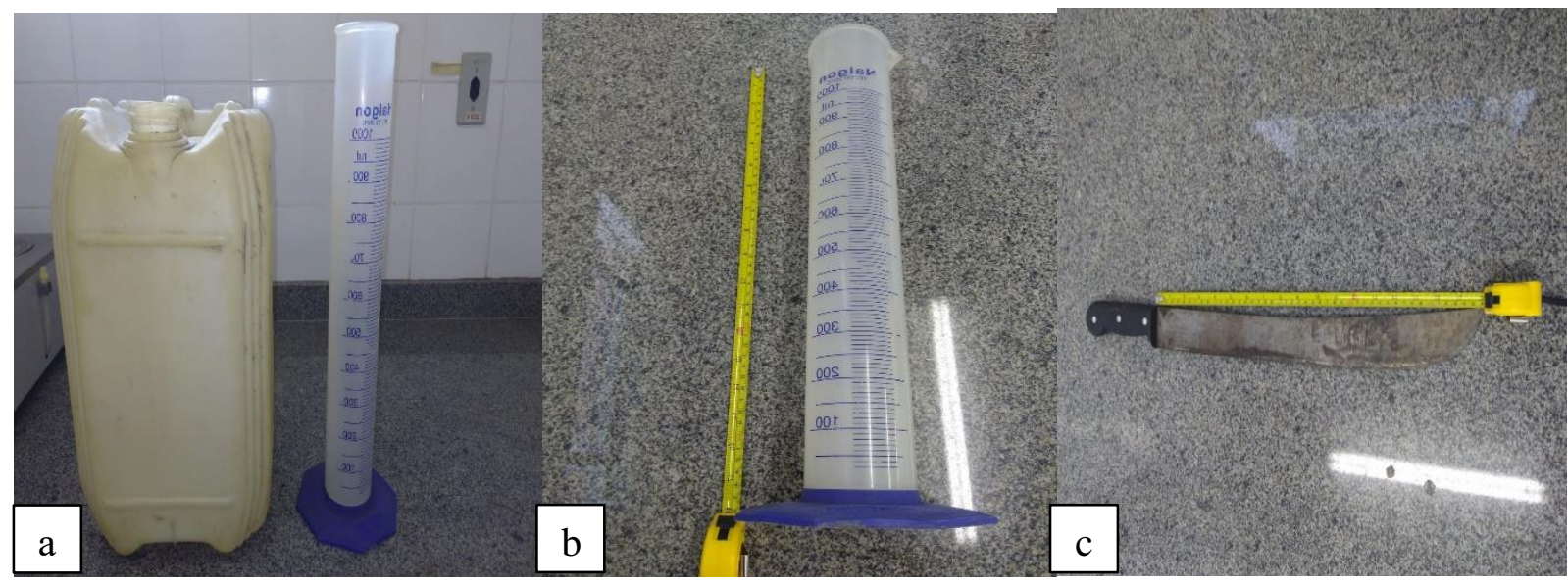

Fonte: autores (2018).

Quanto ao método empregado nesta pesquisa foi utilizado o dedutivo, conforme sintetizado por Prodanov e Freitas (2013), uma vez que por intermédio de duas premissas, 1) as áreas de mata ciliar ao entorno dos corpos hídricos são essenciais à manutenção de tal recurso, bem como à fauna existente nele; 2) há uma grande expansão das construções civis no local da área de estudo, chegouse a uma conclusão: a expansão das construções civis ao entorno do rio Prainha diminuem a área que seria para mata ciliar e, por conseguinte, diminui a capacidade de manutenção do rio. Em relação à pesquisa, a abordagem é quantiqualitativa, com natureza aplicada e objetivo com caráter explicativo. Quanto aos procedimentos técnicos, caracteriza-se como pesquisa experimental.

Esse método foi complementado pelo levantamento de dados documentais, cujo recorte temporal situou-se entre 2009 e 2018, pois, os últimos 5 anos de trabalhos recentes disponibilizaram informações mais atuais e específicas que proporcionaram embasamento teórico para uma melhor avaliação de impacto ambiental. 


\section{FISIOGR AFIA DO MUNICÍPIO}

A área em que foi realizada a pesquisa é o município de Paragominas, fundado em 1965 (Lei

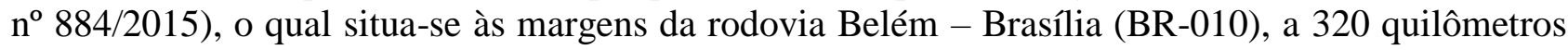
da cidade de Belém, com as coordenadas geográficas 0259'08' S e 47¹9'57' W e com altitude média de $89 \mathrm{~m}$. Além disso, Paragominas possui uma área de aproximadamente 1,93 milhões de hectares (1,5\% da superfície do Pará) e abriga uma população de quase 103.775 mil habitantes (IBGE, 2013).

Ademais, Paragominas apresenta o clima do tipo quente e úmido, com temperatura média anual de $26^{\circ} \mathrm{C}$, pluviosidade média anual de 1.800 milímetros e umidade relativa do ar média de $81 \%$. O município é caracterizado por um período mais chuvoso, entre os meses de dezembro a maio, e os meses de junho a novembro são caracterizados por apresentarem baixa disponibilidade hídrica. Além disso, os principais rios na região são os Capim e Gurupi, como também seus tributários de menor porte, a exemplo, o Rio Cauaxi, o Rio Candiru-Açu e o Potiritá, afluentes do Rio Capim, além dos Rios Piriá e Uraim, afluentes do Rio Gurupi (INMET, 2013; LIMA et al., 2017).

\section{ÁREA DE ESTUDO}

A área escolhida para o estudo está situada no perímetro próximo as margens do rio Prainha, localizado no Bairro Promissão, Paragominas - PA (Figura 4). A descrição da área observada pelo grupo da pesquisa apresenta fortes indicativos do crescimento da urbanização, com números relevantes de domicílios próximos ao entorno do rio. A área próxima ao rio apresenta vegetação rasteira, arbórea e lenhosa, no decorrer do curso do rio e, o trecho analisado contém via asfáltica.

Figura 4 - Mapa político-geográfico de localização da área de estudo. Paragominas - PA.
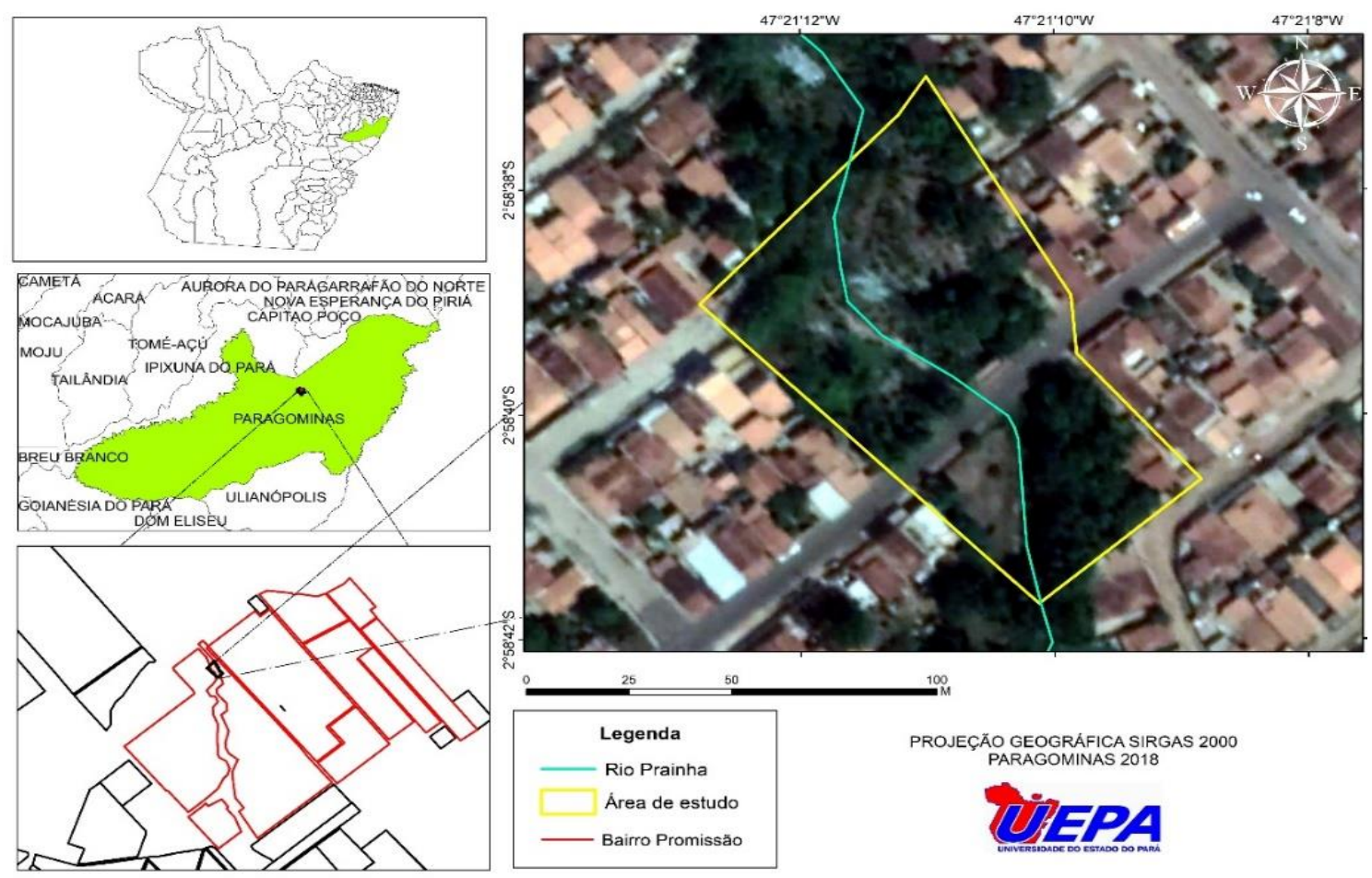

Fonte: Pereira (2018).

Quanto a delimitação do perímetro a ser estudado no entorno do rio, primeiramente foi estabelecido o comprimento de 10,40 metros para demarcação dos pontos e formação de uma área a 
ser estudada, após a marcação do primeiro ponto os demais pontos foram marcados de acordo com o sentido horário (Tabela 2).

Tabela 2 - Coordenadas geográficas dos pontos demarcados para área de estudo. Paragominas - PA.

\begin{tabular}{cccc}
\hline PONTOS & LATITUDE & LONGITUDE & ELEVAÇÃO \\
\hline $\mathrm{P}_{1}$ & $02^{\circ} 59^{\prime} 38,4^{\prime \prime}$ & $47^{\circ} 21^{\prime} 10,4^{\prime \prime}$ & $70 \mathrm{~m}$ \\
$\mathrm{P}_{2}$ & $02^{\circ} 58^{\prime} 38,3^{\prime \prime}$ & $47^{\circ} 21^{\prime} 10,7^{\prime \prime}$ & $69 \mathrm{~m}$ \\
$\mathrm{P}_{3}$ & $02^{\circ} 58^{\prime} 37,9^{\prime \prime}$ & $47^{\circ} 21^{\prime} 10,7^{\prime \prime}$ & $74 \mathrm{~m}$ \\
$\mathrm{P} 4$ & $0258^{\prime} 38,0^{\prime}$, & $47^{\circ} 21^{\prime} 10,3^{\prime \prime}$ & $78 \mathrm{~m}$ \\
\hline
\end{tabular}

Ainda em relação à área de estudo, esta localiza-se na rua Bujaru, situada no bairro Promissão, Paragominas - PA. Quanto a delimitação da área, esta se fez necessário para facilitar a coleta de dados referente a mensuração da velocidade do vento, ao ruído, a luminosidade e a recolha de água, para, posteriormente, mensuração da vazão do corpo hídrico presente no local.

A área de estudo do grupo foi dividida em quatro pontos $\left(\mathrm{P}_{1}, \mathrm{P}_{2}, \mathrm{P}_{3}\right.$ e $\left.\mathrm{P}_{4}\right)$ nos quais foram utilizados os instrumentos e equipamentos para obter os valores do ruído, velocidade, temperatura e luminosidade. Ainda assim, a distância entre cada ponto é de 10,40 metros e a seção entre os pontos foi dividida em três partes (A, B e C), de 3,46 metros. Assim, o primeiro trecho $\left(\mathrm{P}_{1}-\mathrm{P}_{2}\right)$ foi dividido em $\mathrm{A}_{1}, \mathrm{~B} 1$ e $\mathrm{C}_{1} \mathrm{e}$, em cada subdivisão coletado os dados para ruído, velocidade, temperatura e luminosidade e, assim realizado as coletas nos demais trechos da área.

\section{COLETA DE DADOS}

Os dados foram coletados mediante três aulas práticas: $1^{\circ}$ dia, $2^{\circ}$ dia e $3^{\circ}$ dia (Tabela 3 ), no bairro Promissão, com a finalidade de aferir as variáveis velocidade do vento, temperatura atmosférica, ruído, luminosidade na área delimitada a ser estudada e, em trechos do percurso do rio, no qual foi coletado amostras de água na margem e no corpo hídrico para cálculo da vazão.

Tabela 3 - Distribuição das coletas de dados in loco. Paragominas - PA.

\begin{tabular}{|c|c|c|c|c|}
\hline $\begin{array}{c}\text { DIAS DA } \\
\text { VISITA }\end{array}$ & DATA & \multicolumn{2}{|c|}{ HORÁRIOS } & DESCRIÇÃO \\
\hline & & CHEGADA & SAÍDA & \\
\hline $1^{\circ} \mathrm{DIA}$ & $19 / 03 / 2018$ & $15 \mathrm{~h} 15$ & $15 \mathrm{~h} 25$ & $\begin{array}{l}\text { Delimitação dos pontos } \\
\text { perímetro estudado e } \\
\text { luminosidade. }\end{array}$ \\
\hline $2^{\circ}$ DIA & $20 / 03 / 2018$ & $13 \mathrm{~h} 53$ & $14 \mathrm{~h} 05$ & $\begin{array}{l}\text { Coleta de água para mensuração da } \\
\text { vazão do rio, demarcação dos pontos } \\
\text { para aferir a profundidade; } \\
\text { temperatura atmosférica, velocidade } \\
\text { do vento, luminosidade e medição } \\
\text { da largura do rio. }\end{array}$ \\
\hline $3^{\circ}$ DIA & $21 / 03 / 2018$ & $14 \mathrm{~h} 06$ & $17 \mathrm{~h} 10$ & $\begin{array}{l}\text { Verificação da circunferência das } \\
\text { árvores, do ruído, temperatura } \\
\text { atmosférica, velocidade do vento, } \\
\text { coleta de água para cálculo da vazão } \\
\text { na margem do rio e mensuração da } \\
\text { profundidade do rio. }\end{array}$ \\
\hline
\end{tabular}




\section{CÁlCULO DO DiÂMETRO A ALTURA DO PEITO (DAP)}

Para cada árvore presente na área de estudo foi registrada a circunferência a altura do peito CAP, para posterior cálculo do diâmetro a altura do peito (DAP). Assim, de acordo com Arantes (2015), para o cálculo do DAP utiliza-se a medida da circunferência aferida in loco, empregou-se a Equação 1.

em que:

$$
D A P=\frac{C A P}{\pi}
$$

DAP: Diâmetro a Altura do Peito (medido a 1,30m) em cm;

CAP: Circunferência do tronco da árvore, em cm;

$\Pi=3,1416$

\section{CONVERSÃO DE UNIDADE LUX PARA W/M²}

A conversão da unidade de medida convencional fornecida pelo equipamento utilizado, o luxímetro, é o LUX (Lx), tal medida foi convertida para a unidade $\mathrm{W} / \mathrm{m}^{2}$, com o uso da Equação 2 (MINNAERT; VEELAERT, 2010).

$$
1 L U X=1 \text { Lúmen }=\frac{1}{683} \mathrm{~W} / \mathrm{m}^{2}
$$

\section{TRATAMENTO ESTATÍSTICO}

Os dados obtidos foram tratados estatisticamente com o uso de planilhas eletrônicas contidas no software Excel 2013 e BioEstat 5.3, foi empregado a estatística descritiva, pois, pretendia-se simplificar os dados adquiridos. Em relação ao meio sócio econômico, houve a aplicação de formulários na comunidade que residem no entorno do rio, tais formulários foram aplicados em meio um diálogo informal com os moradores do entorno da APP, o que os permitiu ter total liberdade para expor suas opiniões e anseios quanto aos aspectos ambientais questionados (AYRES et al., 2007; FIGUEIREIDO; DALSON; SILVA, 2009).

Para as correlações estatísticas utilizou-se gráficos de dispersão e de acordo com os valores de coeficiente de Pearson - $\mathrm{r}$ e a respectiva classificação (Tabela 4). O coeficiente de Pearson permite uma análise entre a relação de dependência entre fatores distintos (FIGUEIREIDO; SILVA, 2009).

Tabela 4 - Correlação de Pearson

\begin{tabular}{cc}
\hline $\begin{array}{c}\text { Correlação de } \\
\text { Pearson - r }\end{array}$ & Relação \\
\hline $0.10-0.30$ & Fraca \\
$0.40-0.60$ & Moderada \\
$0.70-1.0$ & Forte \\
\hline
\end{tabular}

Fonte: autores (2018).

\section{RESULTADOS E DISCUSSÃO}

\section{MEIO BIÓTICO}

Em relação à vegetação contida na área de estudo, esta é composta de poucas espécies arbóreas, dentre as quais, com predominância de espécies lenhosas, e também por herbáceas. As herbáceas servem como uma camada protetora para o solo, logo, evitam que ocorra processos 
erosivos e auxiliam na recuperação do solo onde estão situadas. Além disso, criam condições favoráveis na superfície para que outras espécies sejam introduzidas e, assim, proporcionam uma base favorável para restauração ou manutenção do ecossistema.

Figura - 5 espécies presentes no perímetro analisado: a) Cajarana (Spondias mombin L.); b) Bananeira (Musa sp.); c) Laranjeira (Citrus spp.). Paragominas - PA.

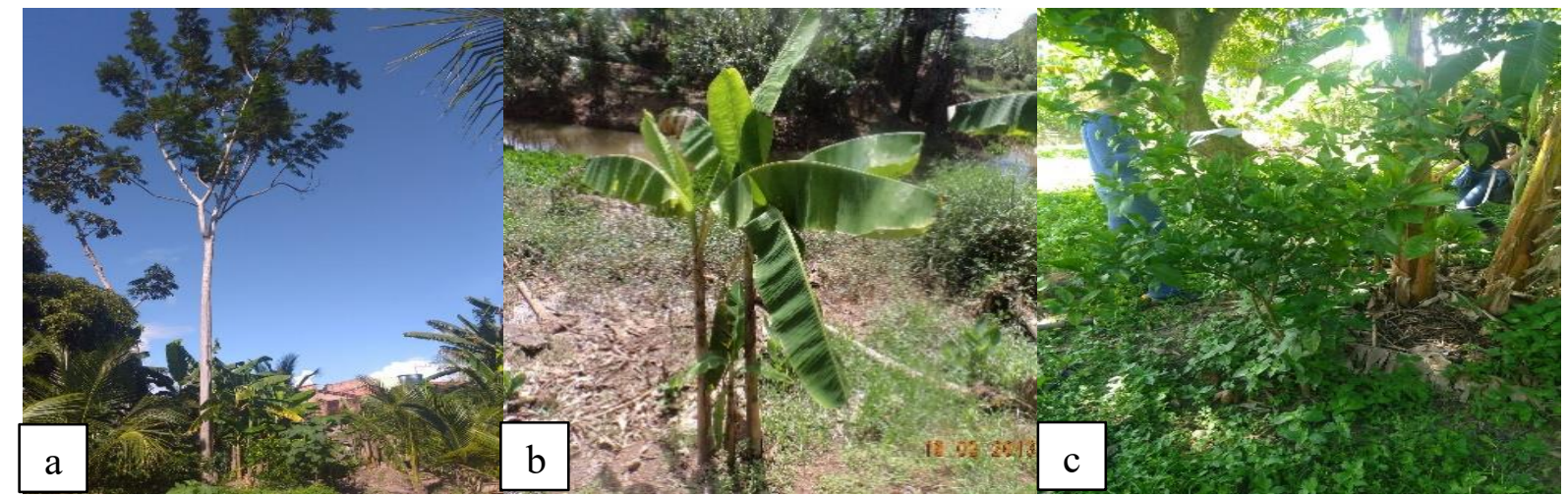

Fonte: autores (2018).

Ainda a respeito da vegetação do local, verificou-se a presença de espécies lenhosas, dentre as quais destaca-se a laranjeira (Citrus spp. L. Osbeck), bananeira (Musa spp.), a mangueira (Mangifera indica L.), a cajarana (Spondias mombin L.) e a Embaúba (Cecropia spp. Löfling). Tais espécies encontravam-se distantes uma das outras, a não ser pela expressiva presença de palmeiras (Arecaceae spp.). próximas, como a formar fileiras. Dessa forma, devido ao espaçamento entre as espécies lenhosas, haviam áreas que recebiam intensa radiação solar, o que, por conseguinte, de acordo com Santos et al. (2012) oferece uma adequada atividade fotossintética à comunidade vegetal.

Dentre as espécies lenhosas identificadas na área de estudo foi calculado o DAP (Tabela 4) para poder avaliar o crescimento da vegetação. Segundo o estudo de Souza et al. (2016), o número de indivíduos nas classes de diâmetro que vão de $12,5 \mathrm{~cm}$ a $32,5 \mathrm{~cm}$, ocorre devido muitas espécies terem sido plantadas no local após o crescimento urbano, e que os indivíduos de diâmetro maiores, são árvores antigas já existentes na localidade.

Tabela 6 - Nome científico e DAP das espécies lenhosas no perímetro estudado e áreas adjacentes. Paragominas - PA.

\begin{tabular}{ccc}
\hline $\begin{array}{c}\text { Espécie } \\
\text { vegetal }\end{array}$ & Nome científico & $\begin{array}{c}\text { Diâmetro a Altura do } \\
\text { Peito (DAP) }\end{array}$ \\
\hline Mangueira & Mangifera indica $\mathrm{L}$. & $29,28 \mathrm{~cm}$ \\
Cajarana & Spondias mombin $\mathrm{L}$. & $20,69 \mathrm{~cm}$ \\
Cajarana & Spondias mombin $\mathrm{L}$. & $29,60 \mathrm{~cm}$ \\
Embaúba & Cecropia spp. Löfling & $27,37 \mathrm{~cm}$ \\
\hline
\end{tabular}

Fonte: autores (2018).

Embora houvesse a presença das espécies vegetais citadas, para uma área de mata ciliar a presença de vegetação no local é considerada escassa, e a diminuição dessa comunidade vegetal influencia fatores como os microclimas urbanos. De acordo com o estudo de Alves e Biudes (2012), a comunidade vegetal atua como filtro ou barreira para a luminosidade, dessa forma com uma menor incidência solar haverá o controle da temperatura, da umidade relativa do ar, da velocidade do vento e, por conseguinte, da formação de chuvas. A medida que a vegetação é primordial para a formação das chuvas, a mesma também ameniza os efeitos da precipitação sobre o solo, ou seja, a vegetação atua tanto em funções de importância macro (formação de chuvas) como micro (controle de processos erosivos no solo) no ambiente. 


\section{A PRESENÇA DE POLINIZADORES}

No local de estudo, notou-se a presença de resíduos sólidos de construção civil (RCC) e doméstico no perímetro analisado. Contudo, a área apresentava significativa existência de insetos polinizadores, como as borboletas, (Lepidoptera - Figura 6a) e libélulas (Odonatas - Figura 6c). Tais presenças são características específicas, as quais permitem inferir sobre a possível qualidade do ambiente, pois, de acordo com o estudo de Macena (2011), a polinização é fator importante não somente para a reprodução das plantas, mas também para a manutenção da rede de interações animais e vegetais, o que caracteriza como serviço de ecossistema básico.

Ademais, as libélulas (Odonatas) são comumente utilizadas como indicadores da qualidade do 'habitat' e na avaliação de impactos ambientais, uma vez que as comunidades de Odonatas podem ser alteradas por modificações das variáveis nos ecossistemas como presença de vegetação marginal, temperatura do ar, concentração de poluentes na água, correnteza e vazão no corpo hídrico (SILVA, 2010; JUEN; MARCO, 2011).

Figura 6 - Presença de Bioindicadores no perímetro analisado. a) Presença de Lepidópteras no perímetro analisado; b) Presença de Joaninha (Coccinelídea); c) Presença de Odonatas. Paragominas - PA.

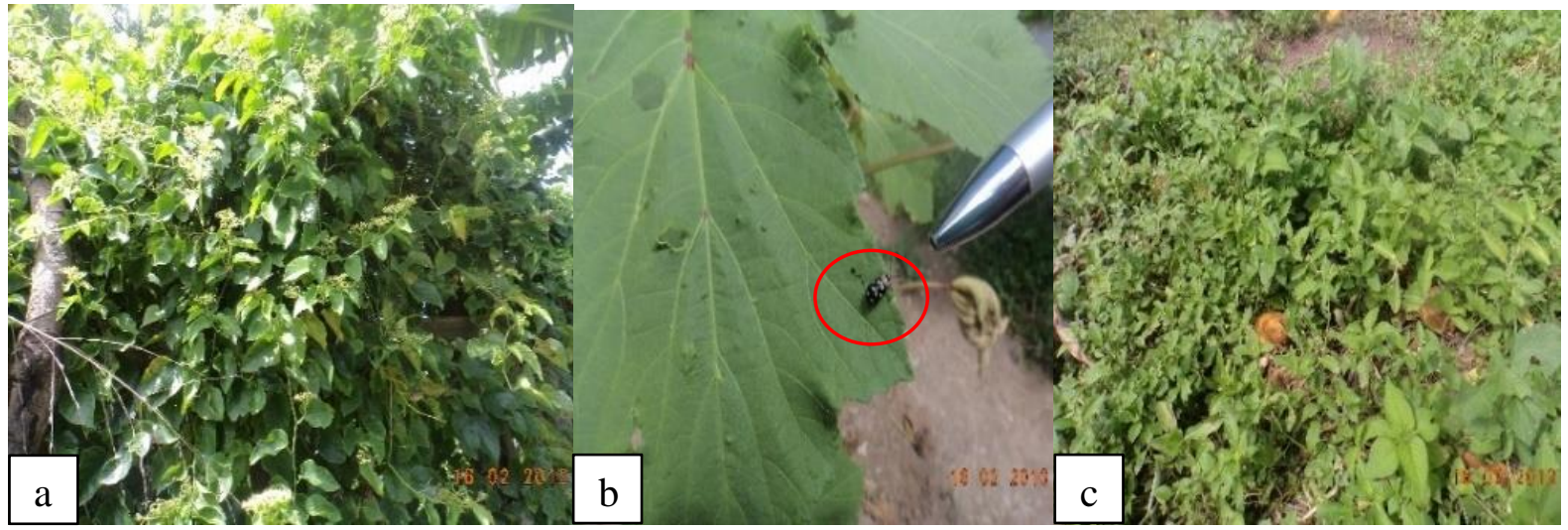

Fonte: autores (2018).

\section{AS CARACTERÍSTICAS DO SOLO}

Em relação ao solo no entorno do curso hídrico, este possuía elevada quantidade de matéria orgânica em decomposição, em decorrência das espécies frutíferas que estão presentes nas áreas adjacentes do perímetro de estudo, como a mangueira (Mangífera Indica). Em alguns trechos do terreno verificou-se coveamentos rasos e mudas recém-plantadas (Figura 7), também apresentava declividade acentuada nas áreas próximas a margem do rio.

Figura 7- Características do solo no perímetro analisado. a) Presença de matéria orgânica; b) Presença de covas para plantação de mudas; c) Presença de vegetação rasteira. Paragominas - PA.

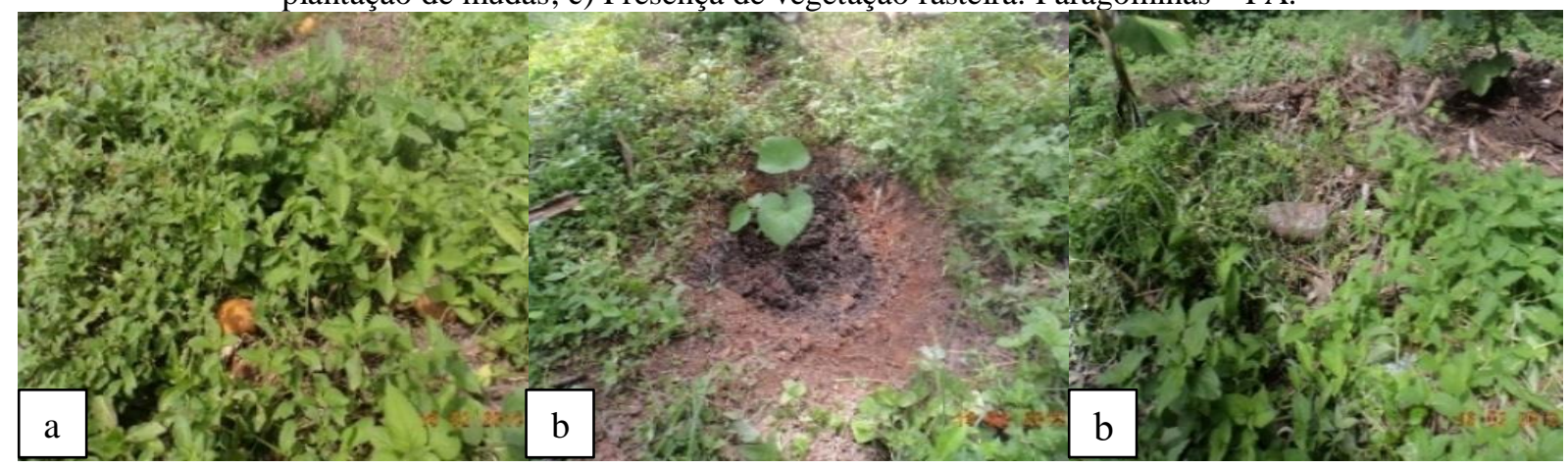

Fonte: autores (2018). 
Quanto ao perímetro da margem do corpo hídrico (Figura 8) percebeu-se que o local apresentava uma grande quantidade de macroalgas adsortivas e macrófitas superficiais ao extremo do rio, além disso, verificou-se que a largura da margem era maior em alguns trechos, e nestes continham a formação de bancos de areia. Tais condições foram resultado do processo de assoreamento sofrido pelo rio e acúmulo de resíduos urbanos à extremidade do mesmo.

Figura 8 - a) Presença de macrófitas na margem do rio; b) Formação de bancos de areia; c) Largura do rio. Paragominas - PA.

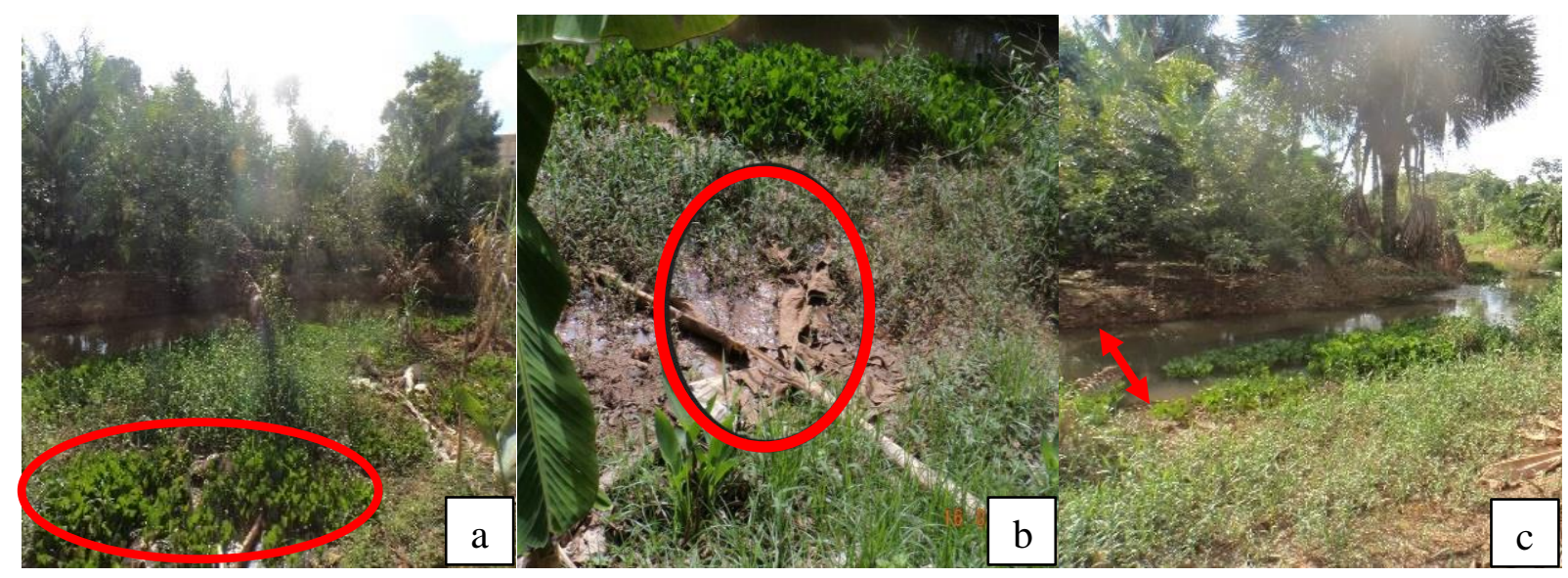

Fonte: autores (2018).

\section{MEIO FÍSICO}

Referente aos parâmetros mensurados no ponto $\mathbf{P}_{1}$ observou-se uma tendência à evolução das variáveis ruído, velocidade do vento e temperatura conforme evolução do fator luminosidade (Tabela $6)$.

Tabela 6 - Fatores abióticos mensuradas na área pesquisada. Paragominas - PA.

\begin{tabular}{cccccc}
\hline $\mathbf{P}_{\mathbf{1}}$ & Unidades & $\mathbf{A}_{\mathbf{1}}$ & $\mathbf{B}_{\mathbf{1}}$ & $\mathbf{C}_{\mathbf{1}}$ & Média \\
\hline Ruído & $\mathrm{d} \beta$ & 52 & 50,5 & 51,2 & 51,23 \\
Velocidade do vento & $\mathrm{m} / \mathrm{s}$ & 1,2 & 0,6 & 0,8 & 0.866 \\
Temperatura & ${ }^{\circ} \mathrm{C}$ & 36,2 & 36,5 & 36,0 & 36,23 \\
Luminosidade & $\mathrm{W}$ & 6,04 & 3,11 & 4,22 & 4,46 \\
\hline
\end{tabular}

Fonte: autores (2018).

A interação entre os parâmetros ambientais mensurados: temperatura versus velocidade do vento (Figura 9a); ruído versus velocidade do vento (Figura 9b) e velocidade do vento e luminosidade (Figura 9c) permitiu analisar a relação de dependência entre tais fatores. 
Figura 9 - Valores médios encontrados para: a) temperatura e velocidade do vento; b) ruído e velocidade do vento; c) velocidade do vento e luminosidade. Paragominas - PA.
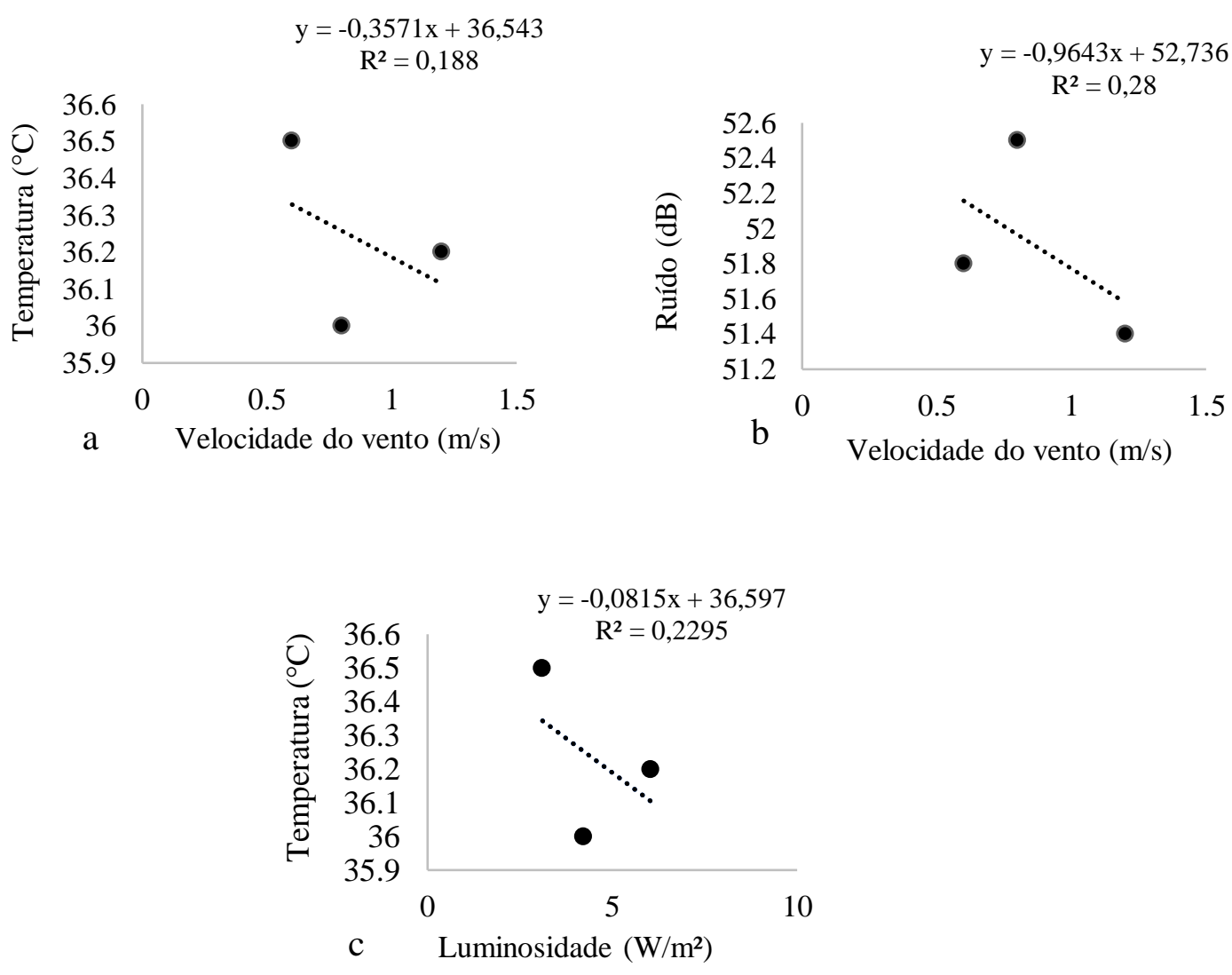

Fonte: autores (2018).

A análise dos dados indicou que a interação entre temperatura e velocidade do vento $(r=$ $0,43)$ é de caráter diretamente proporcional e de grau moderado. No que se refere a tal relação, o estudo de Rolim et al. (2013) na lagoa Mangueira situada entre as cidades Santa Vitória do Palmar e Rio Grande - RS, destacou a relação entre a temperatura e a velocidade do vento, no qual percebeuse que a presença de ventos fortes, ocasionou elevadas variações na temperatura superficial no ecossistema lêntico. No corpo hídrico do presente estudo, no município de Paragominas - PA, os dados obtidos permitiram averiguar que, os baixos índices da velocidade do vento $(1,2 \mathrm{~m} / \mathrm{s} ; 0,6 \mathrm{~m} / \mathrm{s}$; $0,8 \mathrm{~m} / \mathrm{s})$ não interferiram na amenização da temperatura $\left(36,2{ }^{\circ} \mathrm{C} ; 36,5^{\circ} \mathrm{C} ; 36,0^{\circ} \mathrm{C}\right)$ para o ponto $\mathbf{P}_{\mathbf{1}}$.

Os aspectos obtidos também permitiram averiguar, que a relação entre ruído e velocidade do vento é linear negativa de grau moderado $(r=0,52)$, com médias para o ruído e velocidade do vento de $51,23 \mathrm{~dB}$ e $0,86 \mathrm{~m} / \mathrm{s}$, respectivamente.

O estudo de Dias (2012) efetuado na cidade de Porto - Portugal, acerca do som e ruído em jardins urbanos, afirma que, a velocidade da propagação do som varia de acordo com a velocidade e direção do vento, ou seja, dependendo da direção em que as ondas sonoras são emitidas em relação a velocidade do vento, esta pode ser propagada por um longo período no meio ou ser dissipada rapidamente, logo, o ruído é diretamente proporcional a velocidade do vento. No local de estudo, bairro Bujaru, Paragominas - PA, os dados obtidos acerca do ruído e da velocidade do vento permitem inferir que, conforme houve variação da velocidade do vento, simultaneamente, houve variação para os índices de ruído, uma vez que para o maior valor para velocidade do vento $(1,2 \mathrm{~m} / \mathrm{s})$ registrou-se maior índice de ruído (52 dB), o que corrobora com a pesquisa de Dias (2012).

Quanto à interação entre Temperatura e luminosidade, a relação entre estas caracteriza-se como negativa e moderada $(r=0,47)$, ou seja, no ponto analisado a luminosidade não exerceu elevada 
influência sobre o fator temperatura, visto que, a máxima temperatura registrada $\left(36,5^{\circ} \mathrm{C}\right)$ não correspondeu ao maior índice de luminosidade $\left(3,11 \mathrm{~W} / \mathrm{m}^{2}\right)$.

A relação moderada entre a temperatura e luminosidade está em desacordo com o estudo de Santos, Seabra Junior e Nunes (2010) no município de Cáceres - MT, pois os resultados do estudo indicaram que a temperatura sofre influência direta da luminosidade, uma vez que os ambientes que estavam expostos a uma maior incidência luminosa exibiram maiores temperaturas do ar, em ambientes abertos e, em ambientes cobertos a atenuação da temperatura foi proporcional à diminuição da incidência luminosa. Em Paragominas - PA, observou-se que a alta temperatura $\left(36,5^{\circ} \mathrm{C}\right)$ ocorreu para o menor índice de luminosidade $\left(3,11 \mathrm{~W} / \mathrm{m}^{2}\right)$, o que não condiz com a explicação do estudo citado, e pode ter ocorrido devido à presença de alguma espécie arbórea na proximidade em que foi realizada a mensuração.

Quanto aos fatores aferidos no ponto $\mathbf{P}_{2}$ (Tabela 7), verificou-se que não houve elevada variação entre os valores obtidos para ruído, velocidade do vento, temperatura e luminosidade em relação aos valores obtidos no ponto $\mathbf{P}_{\mathbf{1}}$.

Tabela 7 - Fatores abióticos mensurados na área pesquisada. Paragominas - PA.

\begin{tabular}{cccccc}
\hline $\mathbf{P}_{\mathbf{2}}$ & Unidades & $\mathbf{A}_{\mathbf{2}}$ & $\mathbf{B}_{\mathbf{2}}$ & $\mathbf{C}_{\mathbf{2}}$ & Média \\
\hline Ruído & $\mathrm{d} \beta$ & 51,4 & 51,8 & 52,5 & 51,9 \\
Velocidade do vento & $\mathrm{m} / \mathrm{s}$ & 1,0 & 1,1 & 0,4 & 0,83 \\
Temperatura & ${ }^{\circ} \mathrm{C}$ & 37 & 36 & 37 & 36,33 \\
Luminosidade & $\mathrm{w} / \mathrm{m}^{2}$ & 6,04 & 6,04 & 6,07 & 6,04 \\
\hline \multicolumn{5}{c}{ Fonte: autores $(2018)$}
\end{tabular}

Por meio dos dados adquiridos fez-se a correlação dos fatores temperatura e velocidade do vento (Figura 10a); ruído e velocidade do vento (Figura 10b); temperatura e luminosidade (Figura 10c) para atestar o grau de dependência entre estes, uma vez que o ponto $\mathbf{P}_{2}$ situava-se próximo a algumas espécies arbóreas, buscou-se verificar se tais espécies interferiam nos parâmetros analisados.

Figura 10 - Valores médios mensurados para: a) temperatura e luminosidade; b) ruído e velocidade do vento; c) temperatura e luminosidade.
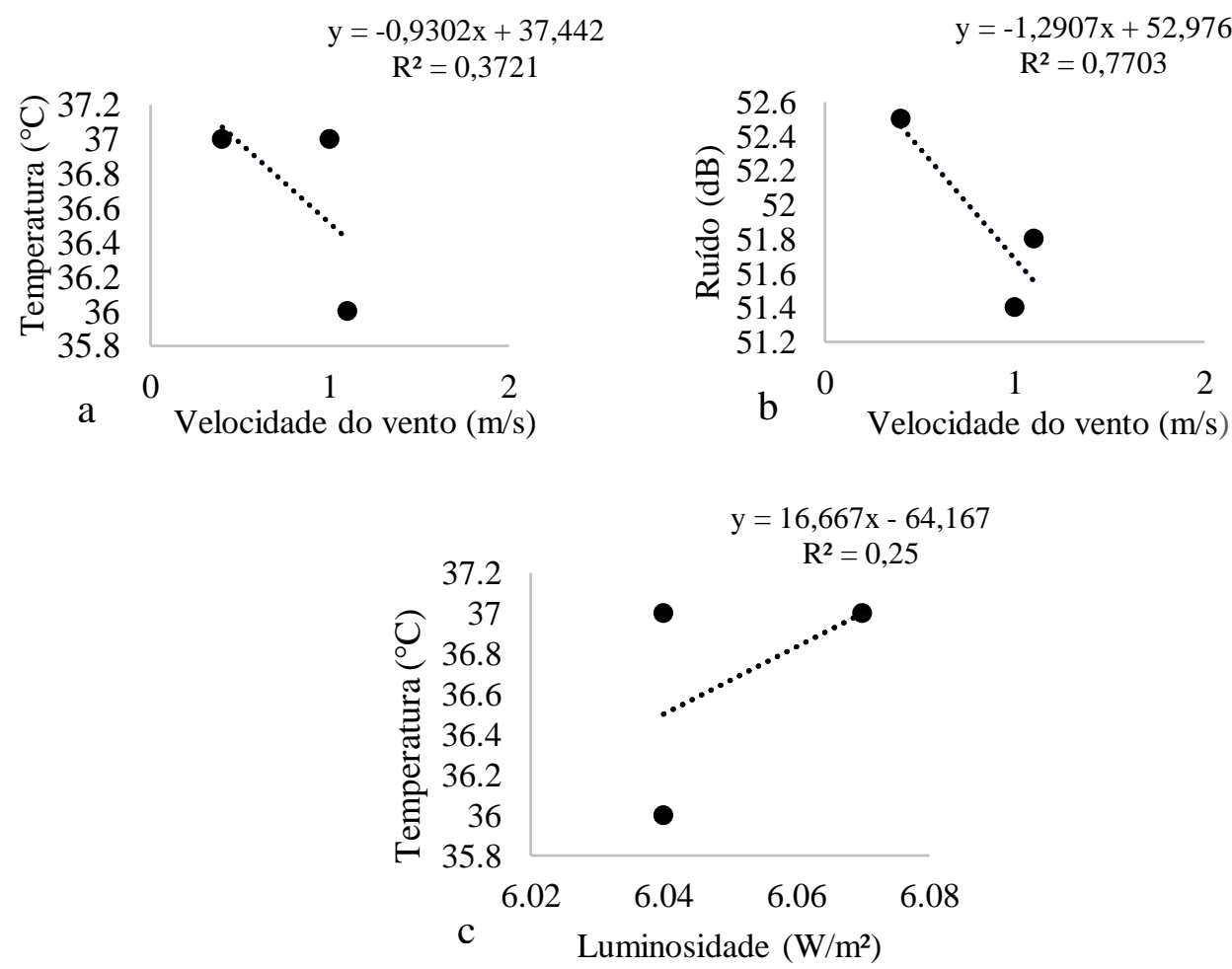

Fonte: autores (2018). 
A apuração dos dados apontou que o grau de dependência entre temperatura e velocidade do vento $(r=0,61)$ é moderada e com tendência negativa, pois a medida que há aumento na velocidade há diminuição da velocidade do vento.

De acordo com o estudo de Gomes e Lamberts (2009) no município de Montes Claros - MG, a velocidade do vento é reduzida em áreas urbanas quando comparada a ambientes rurais e, a ação do vento pode auxiliar na configuração climática urbana, propiciando ar fresco e refrigerado, ou contribuindo para a formação de ilhas de calor pela permuta de energia térmica por convecção. Os dados obtidos no ponto $\mathbf{P}_{2}$ para temperatura e velocidade do vento em Paragominas - PA, permitiram inferir que a baixa velocidade do vento pode estar relacionada a predominância de residências no local de estudo, o que dificulta a movimentação das massas de ar, no entanto, o atrito destas nas estruturas residenciais propicia a troca de calor por convecção, o que pode favorecer a formação de ilhas de calor na área.

Quanto a relação entre ruído e velocidade do vento $(r=0,87)$ esta configura-se como uma correlação forte, uma vez que há expressiva diminuição do índice do ruído com o aumento da velocidade.

Os dados permitem inferir que a reação entre o ruído e a velocidade do vento é inversamente proporcional, mas a diminuição na propagação do ruído no local em que este foi mensurado, pode estar relacionado a outros fatores, além da ação dos ventos. Conforme é explicado pelo estudo de Dias (2012) na cidade do Porto - PT, a interação do vento com outros parâmetros como a temperatura e a umidade do ar podem interferir na propagação do ruído, a exemplo, quando as massas de ar estão mais quentes há uma maior propagação do ruído. Em Paragominas - PA, no local de estudo, as temperaturas elevadas podem ter elevado a temperatura das massas de ar, e, por conseguinte, propiciado condições para elevação dos índices de ruído no meio.

Em relação a interação entre temperatura e luminosidade, esta enquadra-se como moderada $(r$ $=0,5)$ e diretamente proporcional, pois constatou-se que conforme há aumento no índice luminosidade também há elevação nos índices da temperatura. De acordo com a força da correlação fica constatado uma relação de dependência entre os fatores temperatura e luminosidade, pois, a atuação destes configura a desagradável sensação térmica do local de estudo.

Consoante estudos (Lamberts et al., 2011; Oliveira; Alves, 2013; Santos et al., 2012), realizado nos estados de Santa Catarina e, nas cidades de Iporá - GO e em João Pessoa - PB, respectivamente, a temperatura pode variar por fatores como a taxa de cobertura vegetal, luminosidade ou até mesmo a intensidade dos ventos, com atenção para o fator "presença da vegetação", especialmente a arbórea, pois esta proporciona maior absorção da radiação eletromagnética proveniente do sol e, pode influenciar positivamente as condições de conforto térmico dos habitantes, principalmente se situadas próximos de áreas construídas. No entanto, no local de estudo, Paragominas - PA, em que foram mensurados tais parâmetro, a presença de vegetação arbórea, por exemplo, era escassa, fato que contribui para elevação da incidência solar na superfície e, consequentemente, da temperatura.

O estudo de Barbosa e Vecchia (2009) na cidade de São Carlos corrobora com a afirmação de que a presença de vegetação arbórea auxilia na amenização da temperatura urbana, pois, no estudo, as maiores máximas de temperatura $\left(48,7^{\circ} \mathrm{C}\right)$ foram registradas em áreas urbanas como áreas de comércio, serviço e áreas livres, enquanto que as áreas com presença de vegetação as temperaturas registradas foram mais amenas $\left(29,7^{\circ} \mathrm{C}\right)$.

A análise dos fatores abióticos também foi realizada para o ponto $\mathbf{P}_{3}$ (Tabela 8) por meio da mensuração dos parâmetros ruído, velocidade, temperatura e luminosidade. 
Tabela 8 - Fatores abióticos mensurados na área pesquisada. Paragominas - PA.

\begin{tabular}{ccllll}
\hline \multicolumn{1}{c}{$\mathbf{P}_{\mathbf{3}}$} & Unidades & $\mathbf{A 3}_{3}$ & $\mathbf{B 3}$ & $\mathbf{C 3}$ & Média \\
\hline Ruído & $\mathrm{d} \beta$ & 51,6 & 56,0 & 51 & 52,8 \\
Velocidade do vento & $\mathrm{m} / \mathrm{s}$ & 0,5 & 1,2 & 1,4 & 3,1 \\
Temperatura & ${ }^{\circ} \mathrm{C}$ & 37,5 & 37 & 36 & 36,83 \\
Luminosidade & $\mathrm{W} / \mathrm{m}^{2}$ & 6,04 & 6,04 & 6,07 & 6,05 \\
\hline
\end{tabular}

Fonte: autores (2018).

Por meio da correlação entre os fatores abióticos: temperatura versus velocidade do vento (Figura 11a); ruído versus velocidade do vento (Figura 11b); luminosidade versus velocidade do vento (Figura 11c) verificou-se o grau de dependência entre tais parâmetros.

Figura 11 - Valores médios mensurados para os fatores: temperatura e velocidade do vento; ruído e velocidade do vento; temperatura e luminosidade. Paragominas - PA.
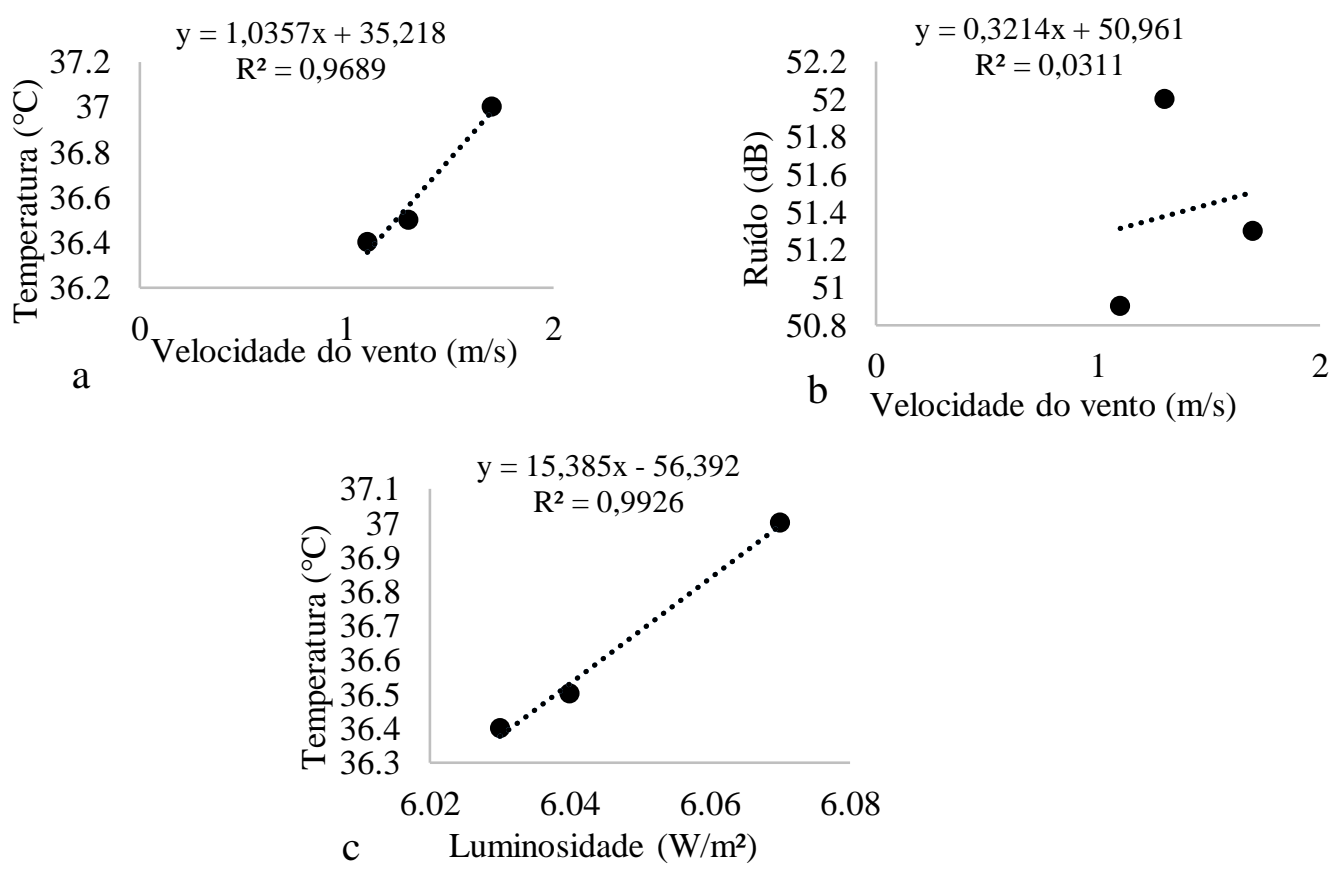

Fonte: autores (2018).

A correlação dos parâmetros ambientais velocidade do vento e temperatura configurou-se como forte $(r=0,98)$ e diretamente proporcional. Acerca dessa interação, foi efetuado um estudo de revisão bibliográfica, por Lamberts et al. (2011). Nele, os autores concluiram que o elevado grau de correlação entre tais parâmetros, é resultado da influência que as massas gasosas exercem sobre a temperatura atmosférica. Em outro estudo, contido no livro denominado "Ambiência Urbana" escrito por Mascaró, L e Mascaró J. (2009), esses autores afirmam que a ocorrência de ventos em áreas com presença de vegetação interage de forma a amenizar a variação da temperatura e da umidade relativa do ar. Em Paragominas, a partir da análise dos dados obtidos, constatou-se que a velocidade do vento exerceu influência para amenizar a temperatura próximo a superfície para o ponto $\mathbf{P}_{3}$, uma vez que, conforme houve aumento no índice de velocidade do vento $(0,5 ; 1,2 ; 1,4 \mathrm{~m} / \mathrm{s})$ houve diminuição nos valores de temperatura $\left(37,5 ; 37,0 ; 36,0^{\circ} \mathrm{C}\right)$, respectivamente.

Quanto a análise da correlação das variáveis ruído e velocidade do vento $(r=0,17)$, esta caracteriza-se como fraca, logo, para o ponto analisado a velocidade do vento não exerceu grande influência na dissipação da energia sonora. No que tange a correlação entre tais variáveis, as elevadas médias registradas $(52,8 \mathrm{~d} \beta$ e $1,03 \mathrm{~m} / \mathrm{s})$ devem estar relacionadas à escassez de árvores no local. Acerca da escassez arbórea, foi realizada uma pesquisa por Cabral (2013).Nela, os dados obtidos 
indicaram que o ruído e a velocidade do vento estão correlacionados à presença de vegetação no ambiente, uma vez que esta reduz a velocidade do vento e absorve ruídos, o que proporciona um equilíbrio ambiental e, evita o cenário de poluição sonora em ambientes urbanos. Na pesquisa realizada em Paragominas observou-se que a parca vegetação na área de estudo favorece a dissipação do ruído, uma vez que não há vegetação suficiente para atuar como barreira acústica no local e, assim, os índices de ruído variam de acordo com fatores como a velocidade do vento, umidade relativa do ar e temperatura.

Em relação a interação entre temperatura e luminosidade, esta enquadra-se como forte $(r=$ 0,99 , e permite inferir que na área do ponto $\mathbf{P}_{2}$, o índice de luminosidade exerceu maior influência sobre a temperatura. A influência da luminosidade sobre a temperatura é perceptível, pois, de acordo com dois estudos efetuados (1) por Giacomeli (2013), em São Carlos - SP, e (2) Martini et al. (2013), na cidade Curitiba - PR. No primeiro, o autor concluiu que, nas áreas com menor incidência solar, há diminuição da transformação da energia radiante em calor sensível, o que reduz os índices de temperatura no local e, em estruturas situadas no entorno. Já no segundo, a conclusão foi de que a variação de temperatura tem relação com a sensação térmica de cada local, esse fenômeno pode ocorrer por influência de diversos fatores abióticos como velocidade do vento e umidade relativa do ar. No estudo efetuado em Paragominas, foi verificado que dentre os parâmetros analisados, velocidade do vento e luminosidade, este último exerceu maior influência para aumento dos índices de temperatura, pois a medida que houve aumento no índice da luminosidade $\left(6,04 \mathrm{~W} / \mathrm{m}^{2} ; 6,07 \mathrm{~W} / \mathrm{m}^{2}\right)$ houve variação no índice de temperatura $\left(37,5^{\circ} \mathrm{C} ; 36,0^{\circ} \mathrm{C}\right)$.

Os dados obtidos para o ponto $\mathbf{P}_{4}$ (Tabela 9) para as variáveis ruído, velocidade do vento, temperatura e luminosidade possibilitaram estabelecer o grau de dependência entre tais parâmetros.

Tabela 7 - Fatores abióticos mensurados na área pesquisada, Paragominas - PA.

\begin{tabular}{cccccc}
\hline $\mathbf{P}_{\mathbf{4}}$ & Unidades & $\mathbf{A 4}_{\mathbf{4}}$ & $\mathbf{B}_{\mathbf{4}}$ & $\mathbf{C}_{\mathbf{4}}$ & Média \\
\hline Ruído & $\mathrm{d} \beta$ & 52,00 & 50,90 & 51,30 & 51,40 \\
Velocidade do vento & $\mathrm{m} / \mathrm{s}$ & 1,30 & 1,10 & 1,70 & 4,10 \\
Temperatura & ${ }^{\circ} \mathrm{C}$ & 36,50 & 36,40 & 37,00 & 36.63 \\
Luminosidade & $\mathrm{W} / \mathrm{m}^{2}$ & 6,04 & 6,03 & 6,07 & 6,05 \\
\hline \multicolumn{5}{c}{ Fonte: autores (2018). }
\end{tabular}

A correlação entre os parâmetros analisados, temperatura versus ruído (Figura 12a), luminosidade versus temperatura (Figura 12b), ruído versus luminosidade (Figura 12c), indica o grau de dependência entre tais parâmetros de acordo com o valor do coeficiente de Pearson. 
Figura 12 - Valores médios mensurados para: a) temperatura e velocidade do vento. b) ruído e velocidade do vento; c) temperatura e luminosidade. Paragominas - PA

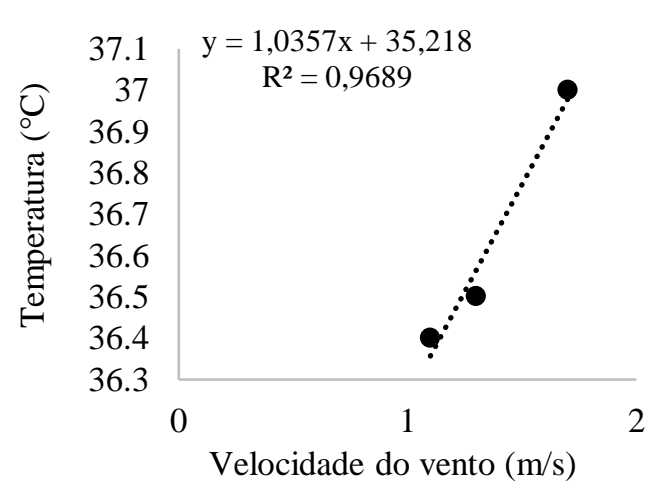

a

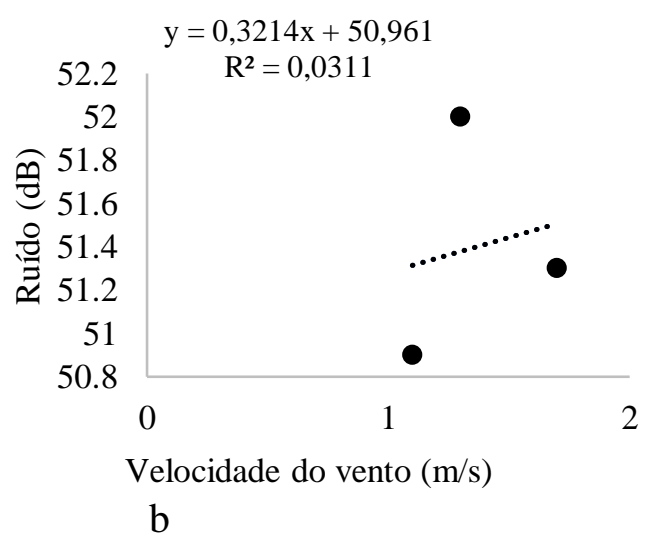

$\mathrm{b}$

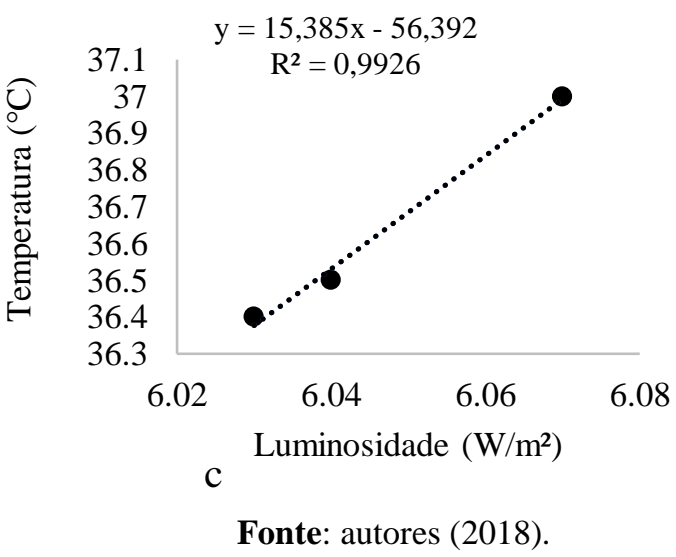

A partir da análise dos dados, constatou-se que a relação entre temperatura e velocidade do vento caracteriza-se como forte $(r=0,98)$ e diretamente proporcional, pois os maiores valores da velocidade do vento corresponderam aos maiores valores da temperatura.

De acordo com Gregory, Luiz Neto e Ribeiro (2018),no estudo realizado em Maceió - AL, a correlação entre temperatura e a velocidade do vento são parâmetros que influenciam diretamente no conforto térmico local, uma vez que o aquecimento das massas de ar influencia a velocidade e direção do vento, ou a ação dos ventos pode proporcionar o resfriamento de ambientes e amenização da temperatura. No local de estudo em Paragominas - PA, a interação entre tais fatores não foi significativa, pois, o maior índice registrado para velocidade do vento $(1,7 \mathrm{~m} / \mathrm{s})$ correspondeu à máxima temperatura registrada $\left(37^{\circ} \mathrm{C}\right)$ no ponto $\mathbf{P}_{\mathbf{4}}$, logo, a relação entre as variáveis no local de estudo não respeita o explicado pelos autores.

A relação entre ruído e velocidade do vento expressa um fraco grau de dependência entre tais fatores $(r=0,17)$ e uma tendência de crescimento positiva. Uma vez que a velocidade do vento não exerceu elevado grau de influência na propagação do ruído, outro fator pode ter contribuído para a elevação do ruído na área, como o fluxo contínuo de automóveis em vias próximas ao local de estudo. Este quadro apresenta-se no estudo de Lima e Carvalho (2010) em seu estudo efetuado no Centro de Mossoró - RN, como fator determinante para a elevação dos níveis de ruídos e a criação de um ambiente sonoro desagradável em áreas urbanas.

Quanto a interação entre temperatura e luminosidade, a relação entre estas configura-se como forte $(r=0,99)$ e diretamente proporcional. Tais fatores também são evidenciados no estudo de Santos et al. (2012), no qual afirma que a presença da vegetação no local acarreta na diminuição da incidência solar na superfície, pois, esta absorve parte da radiação eletromagnética emitida pelo sol, e ameniza a temperatura na superfície, uma vez que tal radiação não aquece as massas de ar das camadas inferiores. Dessa forma, a alta temperatura local é explicada pela diminuição da cobertura vegetal próximo à área de estudo, em virtude do avanço do processo de urbanização no bairro. 
Após a análise comparativa dos principais fatores abióticos, fez-se a correlação entre os valores da vazão calculados para os pontos $\mathbf{P}_{1}, \mathbf{P}_{2} \mathbf{e} \mathbf{P}_{3}$ demarcados no trecho do corpo hídrico na área de estudo (Figura 13).

Figura 13 - valores médios obtidos nos pontos $\mathbf{P}_{\mathbf{1}}, \mathbf{P}_{\mathbf{2}} \mathbf{e} \mathbf{P}_{\mathbf{3}}$. Paragominas - PA. 0.0025

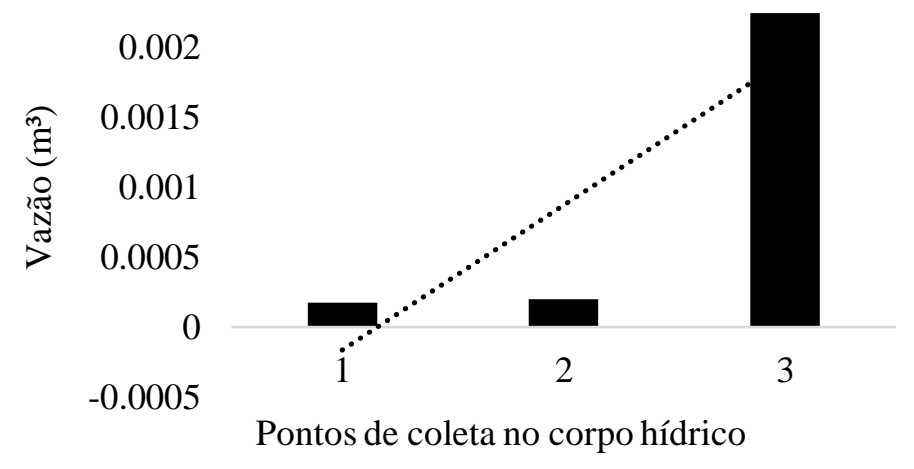

Fonte: autores (2018).

Quanto à média referente a vazão nos pontos demarcados no corpo hídrico, foi considerado o valor da vazão marginal, para mensurar a variação da vazão no meio do rio em relação a margem, pois, a vegetação presente as margens frenam parte da vazão e atua como uma "muralha vegetal". A camada vegetal próxima ao ponto 1 indicou que a frenagem da vazão se dá de maneira extremamente eficiente pelas macrófitas.

Sobre o afloramento de macrófitas, foi efetuado um estudo por um estudo de Ferreira (2012) no município de Pinhais - PR. Esse autor concluiu que o afloramento das macrófitas podem estra relacionados à algumas mudanças no entorno do corpo hídrico, como o lançamento de esgoto doméstico no rio e disposição de resíduos sólidos próximo às margens do corpo hídrico, pois a presença dessas plantas aquáticas indica um aumento na quantidade de nutrientes na superfície do corpo hídrico.

\section{CONCLUSÃO}

O processo de urbanização de forma desordenada que ocorreu o crescimento urbano no bairro em que situa o trecho do rio exerceu sobre o meio biótico foi a supressão vegetal para a construção de unidades arquitetônicas residências e mistas (comercial e residencial), exclusivamente comerciais, uma vez que essa ação desencadeou uma série de alterações nos padrões naturais na APP, pois, houve a retirada da mata ciliar, alargamento da margem do rio, estreitamento do corpo hídrico, diminuição da vegetação arbórea, comprometimento da sobrevivência da fauna, uma vez que é escassa a presença de árvores frutíferas e, dessa forma, diminuição da diversidade biológica nessa área.

De acordo com os dados obtidos referentes aos fatores abióticos, a variável que mais sofreu alteração devido o avanço da urbanização em uma APP foi a luminosidade, com uma média de 5,65 $\mathrm{W} / \mathrm{m}^{2}$, em virtude da retirada expressiva da vegetação arbórea do entorno do corpo hídrico, o que propicia uma maior incidência da radiação solar na superfície o que eleva a temperatura do ar. Ademais, a luminosidade influencia diretamente os fatores velocidade do vento, por conseguinte, é o fator abiótico que mais influencia nas condições de conforto térmico da área.

Assim, é perceptível que o processo de urbanização interfere diretamente nas características do ecossistema natural do entorno do rio. Principalmente devido à baixa sensibilização ambiental da comunidade que habita na zona em que o mesmo se encontra, uma vez que há a disposição incorreta de resíduos sólidos em áreas próximas a margem do rio, como também a presença de RCC. Portanto, a principal interferência da urbanização em relação ao ecossistema foi a remoção da mata ciliar para a construção de residências, pois, assim, foi retirada a proteção natural do corpo hídrico. 


\section{SUGESTÕES DE MELHORIAS AO MEIO BIÓTICO, FÍSICO E SOCIOECONÔMICO}

Com base nos dados apresentados neste trabalho, sugere-se algumas medidas para beneficiar a qualidade ambiental da área do entorno do rio Prainha. Desenvolver ações de educação ambiental e socioeducativas para os habitantes locais, a fim de desenvolver a sensibilidade ambiental e constituir indivíduos capazes de estabelecer ações de autonomia e coletividade, dessa forma, a mitigação dos impactos gerados pela urbanização e a disposição indevida de resíduos sólidos urbanos e domiciliares será mais eficaz.

Conservar as Áreas de Preservação Permanente-APPS, de forma a evitar a supressão da vegetação e o soterramento do perímetro da margem do rio, para que não comprometa as características do corpo hídrico, como a largura e a vazão do rio.

Implantar um projeto para uma rede coletora de esgoto à vizinhança, pois, assim não haverá despejos inadequado de resíduos domésticos no corpo hídrico. Com tal medida seria possível garantir melhores condições de saúde, evitar a contaminação da água e o risco de eutrofização do rio, e diminuir a proliferação de doenças transmitidas por vetores.

Fazer o monitoramento ambiental do corpo hídrico, de forma a examinar parâmetros pertinentes, que possibilitem caracterizar a água de acordo com as normas vigentes, a fim de avaliar as proporções das atividades humanas sobre os sistemas naturais. Tal ação é embasada pelo estudo de Souza e Gastaldini (2014), o qual afirma que o estudo dos padrões de qualidade da água permite um amplo conhecimento do ecossistema e possibilita detectar quais atividades antrópicas prejudicam o equilíbrio do mesmo.

Outra prática que auxiliaria para o retorno do equilíbrio na área de preservação permanente é a restauração da mata ciliar, pois, esta proporcionaria a recuperação das comunidades ecológicas nativas, bem como, influenciariam positivamente à perpetuação das espécies locais.

\section{REFERÊNCIAS}

ALVES, E. D., BIUDES, M. S. Análise da temperatura do ar e da umidade relativa: estudo de microclimas. Interthesis, Florianópolis, v. 9, n. 02, jul. dez, 2012.

ARANTES, A. C. Reposição de biomassa pela supressão de exemplares arbóreos nativos isolados. Revista Ciências Exatas. Rio de janeiro. vol. 21, n. 2, jan./jun., 2015.

AYRES, M.; AYRES JR. M.; AYRES, D. L.; SANTOS, A. A. S. BioEstat 5.0 aplicações estatísticas nas áreas das ciências biológicas e médicas. Belém: IDSM, 364P. 2007.

BARBOSA, R. V. R.; VECCHIA, F. A. S. Estudos de ilhas de calor urbana por meio de imagens do Landsat 7 ETM+: Estudo de caso em São Carlos (SP). Minerva - Pesquisa e Tecnologia. São Carlos -SP, v. 6, n. 3, p. 273-278, 2009.

BITTENCOURT, H. Controle Estatístico da Qualidade. Porto Alegre: 2014.

BRASIL. Conselho Nacional de Meio Ambiente - CONAMA. Resolução no 001 de 23 de janeiro de 1986. Dispõe sobre critérios básicos e diretrizes gerais para a avaliação de impacto ambiental. Diário Oficia da União: Seção 1. Brasília, DF, p. 2548-2549. 1986.

BRANCALION, P. H. S.; VIANI, R. A. G.; RODRIGUES, R. R.; GANDOLFI, S. Avaliação e monitoramento de áreas em processo de restauração. Piracicaba, SP: LASTROP, 2015. 
CABRAL, P. I. D. Arborização urbana: problemas e benefícios. Revista Especialize On-line IPOG. Goiânia, v. 1, n. 6, p. 15, 2013.

DIAS, R. A. C. F. O som e o ruído nos jardins urbanos. 2009. Dissertação (Mestrado em Engenharia do Ambiente) - Faculdade de Engenharia, Universidade do Porto, Porto - Portugal, 2009.

FERREIRA, S. C. R. Estudo da qualidade dos corpos hídricos do Parque das Águas em Pinhais/PR. 2012. 108 p. Dissertação (Mestrado em Ciências e Tecnologia Ambiental). Universidade Tecnológica Federal do Paraná. 2012.

FIGUEIREDO. F.; DALSON, B.; SILVA, J. Desenvolvimento os Ministérios do Coeficiente de Correlação de Pearson (r). Revista Política Hoje, v.18, n.1, p. 115-146, 2009.

GILBUENA, R.; KAWAMURA, A.; MEDINA, R.; AMAGUCHI, H.; NAKAGAWA, N.; BUI, D. D. Environmental impact assessment of structural flood mitigation measures by a rapid impact assessment matrix (RIAM) technique: A case study in Metro Manila, Philippines. Science of the Total Environment, v. 456-457, p. 137-147, 2013.

GOMES, P. S.; LAMBERTS, R. O estudo do clima urbano e a legislação urbanística: considerações a partir do caso Montes Claros, MG. Ambiente Construído, Porto Alegre - RS, v. 9, n.1, p. 73-91, jan./mar., 2009.

GREGORY, J.; LUIZ NETO; RIBEIRO, S. A ventilação natural e insolação: a contribuição no desempenho térmico no projeto de uma pousada na orla de Maceió/AL. Ciências Humanas e Sociais, Alagoas, v. 5, n. 1, p. 97-114, nov., 2018.

IBGE. Instituto Brasileiro de Geografia e Estatística. Pesquisa de informações básicas municipais. Rio de Janeiro: IBGE, 2013. Disponível em: 〈http://www.ibge.gov.br/cidadesat/topwindow.htm?1〉. Acesso em: 21 mar. 2018.

INMET. Instituto Nacional de Meteorologia. 2013. Disponível em: <http:// www.inmet.gov.br/portal>. Acesso em: 21 mar. 2018.

JATOBÁ, S. U. S. Urbanização, meio ambiente e vulnerabilidade social. Boletim Regional, Urbano e Ambiental. Instituto de Pesquisa Econômica Aplicada - IPEA. Diretoria de Estudos e Políticas Regionais, Urbanas e Ambientais. n. 5, p. 141-148, jun., 2011.

JUEN, L.; MARCO, P. Odonate biodiversity in terra-firme forest streamlets in Central Amazonia: on the relative effects of natural and niche drivers at small geographical extents. Insect Conservation and Diversity, v.4, p. 265-274, 2011.

LAMBERTS, R.; XAVIER, A. A.; GOULART, S., VECCHI, R. D. Conforto e stress térmico. Laboratório de Eficiência Energética em Edificações - LabEEE, Universidade Federal de Santa Catarina - UFSC. 2011.

LEVINO, N. A; MORAES, D. C. Análise da degradação ambiental do Complexo Estaurino-Lagunar Mundaú/Manguaba - Alagoas. In: SIMPÓSIO BRASILEIRO DE ENGENHARIA DE PRODUÇÃO. 16., Bauru, Anais [...]. Bauru. 2009. 
LIMA, A. G. M.; CARVALHO, R. G. Poluição Sonora no meio ambiente urbano - caso centro de Mossoró, Rio Grande do Norte, Brasil. Revista Eletrônica do Prodema, Fortaleza, v. 5, n. 2, p. 69 87, jun. 2010.

LIMA, I. V.; SILVA, M. B.; ADAMIL, M.; PINHEIRO, A. F.; BARROS, M. N. R.; NARVARES, I. S.; GOMES, A. R.; WATRIN, O. S.; MAGNO JÚNIOR, P. S. L.; ROCHA, E. S. Dinâmica das áreas de reflorestamento no município de Paragominas, Estado do Pará, considerando dados temporais do projeto TerraClass. In: SIMPÓSIO BRASILEIRO DE SENSORIAMENTO REMOTO -SBSR, 18., Anais [...]. São Paulo, mai. 2017.

MASCENA, V. M. Abelhas visitantes florais, potenciais polinizadores do algodoeiro (Gossypium hirsutum L.) em cultivo agroecológico. 2011. Dissertação (Mestrado em Zootecnia) Universidade Federal do Ceará, Fortaleza, 2011.

MARTINI. A; BIONDI, D; BATISTA. A. C; ZAMPRONI, K. A periodicidade diária do índice de conforto térmico na arborização de ruas de Curitiba-PR. Scientia Plena, v. 9, n, 5, 2013.

MASCARÓ, L.; MASCARÓ, J. J. Ambiência urbana, 3. Ed. Porto Alegre: +4editora, 2009, 200p.

MINNAERT, B.; VEELAERT, P. The suitability of organic solar cells for different indoor conditions. Advances in Science and Technology, v. 74, p. 170-175, 2010.

OLIVEIRA, M. M. F.; ALVES, W.S. A influência da vegetação no clima urbano de cidades pequenas: um estudo sobre as praças públicas de Iporá-GO. Territorial, Goiás, v. 2, p. 61-77, 2013.

PRODANOV, C. C; FREITAS, E. C. Metodologia do trabalho científico: métodos e técnicas da pesquisa e do trabalho acadêmico. 2 ed. Rio Grande do Sul: Feevale. 2013.

ROLIM, S. B. A.; XAVIER, M. B.; DEGRAZIA, G. A.; MOOR, L. P.; PEREIRA FIHO, W. Estudo da temperatura superficial de lagoas costeiras através de parâmetros meteorológicos e dados de sensoriamento remoto. Ciência e natura. Santa Maria, ed. Especial, dez., p. 534-537, 2013.

SÁNCHEZ, L. E. Avaliação de impacto ambiental: conceitos e métodos. 2. ed. São Paulo: Oficina de Textos, 2013.

SANTOS, J. S. SILVA, V. P. R.; LIMA, E. R. V.; ARAÚJO, L. E., COSTA, A. D. L. Campo térmico urbano e sua relação com o uso e cobertura do solo em cidade tropical úmida. Revista Brasileira de Geografia Física, Recife, v. 03, p. 540-557, 2012.

SANTOS, L. L.; SEABRA JUNIOR, S.; NUNES, M. C. M. Luminosidade, temperatura do ar e do solo em ambientes de cultivo protegido. Ciências Agroambientais, Alta Floresta, v. 8, n. 1, p. 8393, 2010.

SANTOS, I. D C. A avaliação de impacto ambiental e a responsabilidade do Brasil diante da degradação ao meio ambiente. Interfaces Científicas, Aracajú, v. 1, n. 2, p.67-74, fev. 2013.

SILVA, D. P.; MARCO, P.; RESENDE, D. C. Adult odonate abundance and community assemblage measures as indicators of stream ecological integrity: A case stud. Ecological Indicators, v. 10, p.744-752. 2010. 
SILVA, R.; SANTOS, V.; GALDINO, S. Análise de impactos ambientais da urbanização sobre os recursos hídricos na sub-bacia do córrego vargem grande em Montes Claros-MG. Caderno de Geografia, Minas Gerais, v.26, n.47, p. 966-976, jul. 2016.

SOUZA, S. R.; MACIEL, M. N. M.; OLIVEIRA, F. A.; JESUÍNO, S. A. Caracterização do conflito de uso e ocupação do solo nas áreas de preservação permanente do Rio Apeú, Nordeste do Pará. Floresta, Curitiba, v. 42, n. 4, p. 701 - 710, out./dez. 2012.

SOUZA, M. M; GASTALDINI, M. C. Avaliação da qualidade da água em bacias hidrográficas com diferentes impactos antrópicos. Engenharia Sanitária e Ambiental, Rio de Janeiro, v. 19, n. 3, p. 263-274, jul./set. 2014.

VARJABEDIAN. R; MECHIL. A. As APP's de topo de morro e a Lei 12.651/12. In: Congresso Brasileiro De Geologia De Engenharia E Ambiental, 14., 2013, Rio de Janeiro. Anais eletrônicos. Disponível em: http://www.abge.org.br/site/produto/13-congresso-brasileiro-de-geologia-deengenharia-e-ambiental-e-coletanea-dos-anuais-do-cbge/ Associação Brasileira de Geologia e Ambiental, Rio de Janeiro. 2013. Acesso em 20 fev. 2019.

Sara Dorea de Oliveira Santos Concluinte do curso de Engenharia Ambiental Universidade do Estado do Pará Departamento de Engenharia Ambiental saraddorea@gmail.com

Andreza Silva e Silva

Concluinte do curso de Engenharia Ambiental

Universidade do Estado do Pará

Departamento de Engenharia Ambiental andrezasilva.s2507@gmail.com

Luana Lima Souza

Concluinte do curso de Engenharia Ambiental Universidade do Estado do Pará Departamento de Engenharia Ambiental lulsouzaeng2015@gmail.com

Ronilson Rosário Lobo

Concluinte do curso de Engenharia Ambiental

Universidade do Estado do Pará

Departamento de Engenharia Ambiental ronilsonlobo@gmail.com

Antônio Pereira Júnior Mestre em Ciências Ambientais Universidade do Estado do Pará Departamento de Engenharia Ambiental antonio.junior@uepa.br 